\title{
Effects of cerebroplegic solutions during hypothermic circulatory arrest and short-term
}

\section{recovery}

Previous studies have suggested that a simple crystalloid "cerebroplegic" solution may prolong the safe duration of hypothermic circulatory arrest. We tested the hypothesis that pharmacologic modification of the cerebroplegic solution would further enhance cerebral protection. Forty-six 4-week-old miniature piglets underwent core cooling to $15^{\circ} \mathrm{C}$ nasopharyngeal temperature and 2 hours of hypothermic circulatory arrest. Twelve animals had a $50 \mathrm{ml} / \mathrm{kg}$ dose of saline infused into the carotid artery system at the onset of hypothermic circulatory arrest and repeat doses of $10 \mathrm{ml} / \mathrm{kg}$ every 30 minutes during arrest. Eleven animals received the same initial and repeat doses of University of Wisconsin organ preservation solution and 10 received University of Wisconsin solution with $7.5 \mathrm{mg} / \mathrm{L}$ of MK-801, an excitatory neurotransmitter antagonist. In 13 control animals blood was partially drained from the piglet before 2 hours of circulatory arrest at $15^{\circ} \mathrm{C}$ and no cerebroplegic solution was infused. All solutions were delivered at $4^{\circ} \mathrm{C}$. Brain temperature $(n=24)$ at the onset of hypothermic circulatory arrest was $15.0^{\circ} \pm 0.1^{\circ} \mathrm{C}$ (mean \pm standard error). Brain temperature after cerebroplegic infusion dropped to $13.0^{\circ} \pm 0.3^{\circ} \mathrm{C}$ and stayed lower than brain temperature in the control group throughout the hypothermic circulatory arrest period. Recovery of cerebral adenosine triphosphate and intracellular pH determined by phosphorus 31 magnetic resonance spectroscopy $(n=22)$ was significantly improved by saline infusion and was further improved with University of Wisconsin solution and University of Wisconsin solution plus MK-801 $(p<0.001)$. Recovery of cerebral blood flow measured by microspheres $(n=24)$ also was augmented by University of Wisconsin solution $(p<0.001)$ but not in the presence of MK-801. The vascular resistance response to acetylcholine and nitroglycerin suggested that MK-801 has a direct vasoconstrictive effect. Recovery of cerebral oxygen consumption $(n=24)$ was increased by University of Wisconsin solution and University of Wisconsin solution with MK-801 $(p=0.002)$. Brain water content $(n=46)$ was significantly lower in all cerebroplegia-treated groups than in controls $(p<0.001)$. Conclusion: Cerebroplegia improves short-term recovery after 2 hours of circulatory arrest in hypothermic piglets. Pharmacologic modification with University of Wisconsin solution further improves the recovery of cerebral blood flow and metabolism. MK-801 does not augment the protective effects of University of Wisconsin solution and reduces the recovery of cerebral blood flow by a direct vascular action. Modified cerebroplegia may provide a novel approach to improved cerebral protection when prolonged hypothermic circulatory arrest is necessary. (J THOrac Cardiovasc Surg 1994;108:291-301)

Mitsuru Aoki, MD, Richard A. Jonas, MD, Fumikazu Nomura, MD, Michael E. Stromski, MD, Miles K. Tsuji, MD, Paul R. Hickey, MD, and David Holtzman, MD, Boston, Mass.

From the Departments of Cardiac Surgery, Neonatology, Anesthesia, and Neurology, Children's Hospital, the Departments of Surgery, Pediatrics, Anesthesia, and Neurology, Harvard Medical School, and the Department of Radiology, Brigham and Women's Hospital, Boston, Mass.

Funded in part by National Institutes of Health grant RR-00995 and by the Cardiovascular Surgery Research Fund at Children's Hospital.
Received for publication Aug. 16, 1993.

Accepted for publication Jan. 9, 1994.

Address for reprints: Richard A. Jonas, MD, Department of Cardiac Surgery, Children's Hospital, 300 Longwood Ave., Boston, MA 02115 .

Copyright $\odot 1994$ by Mosby-Year Book, Inc.

$0022-5223 / 94 \$ 3.00+0 \quad \mathbf{1 2} / \mathbf{1} / \mathbf{5 4 5 2 3}$ 
Deep hypothermic circulatory arrest facilitates the repair of congenital heart defects in infants and neonates, especially for operations involving the aortic arch. Systemic hypothermia to $15^{\circ}$ to $18^{\circ} \mathrm{C}$ alone does not provide satisfactory cerebral protection during relatively long (greater than 45 minutes) periods of circulatory arrest. ${ }^{1}$ Previous studies have suggested that intermittent perfusion of the brain with a simple crystalloid solution may improve cerebral protection by preserving high-energy phosphates and thereby prolong the safe duration of circulatory arrest. $^{2,3}$ Such a solution has previously been termed cerebroplegia, which we define as an asanguineous solution infused through the cerebral circulation during a period of global ischemia to minimize the deleterious effects of ischemia and subsequent reperfusion. In the present study we used a juvenile piglet model to explore the effects of pharmacologic manipulation of cerebroplegic solutions on recovery of cerebral blood flow and metabolism using University of Wisconsin (UW) solution and an excitatory neurotransmitter antagonist, MK-801 . We chose to study asanguineous solutions because our previous studies have shown that activation of blood protease cascades ${ }^{4}$ and leukocytes* play important roles in the pathogenesis of brain injury after hypothermic cardiopulmonary bypass (CPB) and circulatory arrest. Furthermore, partial oxygen or substrate supply during cerebral ischemia can exacerbate accumulation of toxic metabolites. ${ }^{5}$

\section{Materials and methods}

Experimental preparation. Forty-six Yucatan miniature piglets (mean age $29.5 \pm 0.3$ [standard error] days, mean weight $3.9 \pm 0.3 \mathrm{~kg}$ ) (Charles River Laboratories, Wilmington, Mass.) were studied in compliance with the "Principles of Laboratory Animal Care" formulated by the National Society for Medical Research and the "Guide for the Care and Use of Laboratory Animals" prepared by the National Academy of Sciences and published by the National Institutes of Health (NIH Publication No. 86-23, revised in 1985). The animals were obtained 1 to 2 days before the study and fasted for 12 hours before the operation.

In 24 piglets, cerebral blood flow and oxygen and glucose consumption were studied by means of techniques that have been described previously. ${ }^{6}$ Animals were anesthetized with intraperitoneal injection of methohexital $(40 \mathrm{mg} / \mathrm{kg})$ and their lungs were ventilated with $100 \%$ oxygen to achieve arterial carbon dioxide tension of 35 to $45 \mathrm{~mm} \mathrm{Hg}$. Venous and arterial catheters were inserted through the right femoral vein and artery into the thoracic inferior vena cava and aorta, respectively. After a bolus intravenous injection of fentanyl $20 \mu \mathrm{g} / \mathrm{kg}$ and pancuronium $0.3 \mathrm{mg} / \mathrm{kg}$, anesthesia was maintained with con-

*Aoki M, Jonas RA, Nomura F, Kawata H, Hickey PR. Impact of monoclonal antibody to leukocyte adhesion molecule CD18 on del- eterious effects of cardiopulmonary bypass and hypothermic circulatory arrest in immature piglets. Unpublished data. tinuous infusion of fentanyl ( $25 \mu \mathrm{g} / \mathrm{kg}$ per hour) and pancuronium $(0.1 \mathrm{mg} / \mathrm{kg}$ per hour $)$. The animal's temperature was monitored throughout the study by rectal and nasopharyngeal temperature probes (Yellow Springs Instrument Co., Yellow Springs, Ohio). Temperatures were maintained above $35^{\circ} \mathrm{C}$ except for the period of induced hypothermia. A 30-gauge needle temperature probe (model HYP-1, Omega Engineering, Inc., Stamford, Conn.) with polystyrene plastic for support was inserted $15 \mathrm{~mm}$ deep into the right occipital region of the brain through a $1 \mathrm{~mm}$ burr hole in the skull for continuous monitoring of brain temperature.

The heart was exposed through a median sternotomy incision. The brachiocephalic trunk, which divides into the right and left common carotid arteries beyond the takeoff of the right subclavian artery, was exposed. The right subclavian artery was dissected and a $6 \mathrm{~F}$ catheter was inserted retrogradely into the artery to the point of vertebral artery takeoff for infusion of cerebroplegic solutions and pressure monitoring in the carotid artery system. All branches of the subclavian artery except the vertebral artery were ligated. A snare with a tourniquet was passed around the common carotid trunk for occlusion during circulatory arrest. A $4 \mathrm{~mm}$ diameter electromagnetic flow probe (FB-040, Nihon Kohden, Tokyo, Japan) was placed on the now single common carotid trunk to assess the carotid arterial blood flow by a flowmeter (MFV-3 100, Nihon Kohden). A 5F sampling catheter was inserted retrogradely through the right internal jugular vein to the level of the jugular bulb. Position of the catheter tip was determined by measurement in all animals, as well as by dissection at the end of the study in preliminary experiments. The piglet was fully heparinized $(300 \mathrm{IU} / \mathrm{kg})$ and a $10 \mathrm{~F}$ arterial cannula and a $20 \mathrm{~F}$ to $24 \mathrm{~F}$ venous cannula were inserted through pursestring sutures in the ascending aorta and into the right atrial appendage, respectively, for institution of CPB. The pump-oxygenator system consisted of a roller pump and a Bio-2 infant bubble oxygenator (Baxter Healthcare Corp., Bentley Laboratories Div., Irvine, Calif.). Venous drainage was accomplished by gravity. No arterial filter was used. After systemic heparinization, shed blood in the operating field was returned to the system through a $20 \mu \mathrm{m}$ transfusion filter. An electromagnetic flow probe (FF-060T, Nihon Kohden) was placed on the arterial perfusion tubing to verify the pump flow rate. The pump-oxygenator system was primed with $400 \mathrm{ml}$ of heparinized homologous blood collected 2 days before the study (Charles River Laboratories) and $350 \mathrm{ml}$ of electrolyte solution (Normosol-R pH 7.4; Abbott Laboratories, North Chicago, Ill.) to achieve a hematocrit value of $20 \%$ to $25 \%$. To mimic our clinical application of hypothermic circulatory arrest, we added methylprednisolone $30 \mathrm{mg} / \mathrm{kg}$, cephazolin sodium $25 \mathrm{mg} / \mathrm{kg}$, and enough sodium bicarbonate to achieve a $\mathrm{pH}$ of 7.4 to the prime. The electrolyte solution (Normosol-R pH 7.4), containing heparin $2500 \mathrm{IU} / \mathrm{L}$, was used when reservoir volume decreased during bypass. Temperature of the perfusate was controlled by the heat exchanger within the oxygenator and a water bath system warmed by a thermostat-controlled heatercirculator. During the cooling phase, ice water was circulated.

Perfusion protocol. Bypass flow was set at $150 \mathrm{ml} / \mathrm{kg}$ per minute calibrated at a perfusate temperature of $37^{\circ} \mathrm{C}$. The alpha-stat strategy of acid-base management during hypothermia was accomplished by adjusting the flow of $100 \%$ oxygen to the oxygenator. The piglet was initially perfused for 20 minutes at normothermia $\left(37^{\circ} \mathrm{C}\right.$ arterial temperature) to stabilize body temperature and metabolism. The baseline measurements were 
made at the end of this period. Then the perfusate was cooled to an arterial temperature of $13^{\circ} \mathrm{C}$, with a gradient of less than $10^{\circ} \mathrm{C}$ being maintained between blood and nasopharyngeal temperatures. Ice packs were placed around the head throughout the cooling and hypothermic circulatory arrest periods. After 30 minutes of perfusion cooling, when nasopharyngeal temperature was $14.0^{\circ}$ to $15.0^{\circ} \mathrm{C}$, the second measurements were made. The carotid trunk snare was tightened (complete occlusion was confirmed by a drop in pressure monitored from the right subclavian artery line). The perfusion was stopped for 2 hours. Blood was drained through the venous drainage line for 2 minutes, and then arterial and venous lines were clamped. No cardioplegic solution was given. Reperfusion was begun at 150 $\mathrm{ml} / \mathrm{kg}$ per minute with the perfusate at room temperature $\left(20^{\circ}\right.$ to $25^{\circ} \mathrm{C}$ ) and then rewarmed to $37^{\circ} \mathrm{C}$ by circulating warm water $\left(40^{\circ} \mathrm{C}\right)$ to the oxygenator. Boluses of phentolamine $(0.2$ $\mathrm{mg} / \mathrm{kg}$ ) were given at the beginning of both the cooling and rewarming periods as is done in our clinical practice. Sodium bicarbonate $(8.4 \%, 10 \mathrm{ml})$ was given after 5 minutes of reperfusion to correct metabolic acidosis. Additional bicarbonate was given when blood $\mathrm{pH}$ was less than 7.30 but not immediately before measurements. Measurements were made at 5 minutes after reperfusion and at 45 minutes, by which time normothermia was achieved. When the animal was normothermic, ventilation was restarted and the pump perfusion was continued for 3 hours with the blood temperature at $37^{\circ} \mathrm{C}$ to ensure adequate perfusion without inotropic support, as well as stable body and brain temperature. During the last 3 hours of normothermic perfusion, pulsatile assistance from the heart was achieved by raising central venous pressure minimally $(<5 \mathrm{~mm} \mathrm{Hg})$. At the end of the study, the animal was killed by a bolus injection of Beuthanasia (Schering, Kenilworth, N.J.) and potassium chloride in to the circuit.

Another set of 22 animals that underwent the same surgical procedure and CPB as described earlier were studied with phosphorus 31 magnetic resonance spectroscopy (MRS) with an Oxford horizontal-bore superconducting 4.7 magnet (Oxford Research Systems, Oxford, England), as described previously in detail. ${ }^{6}$ A $3.0 \mathrm{~cm}$ diameter surface coil was sutured on the scalp overlying the cerebral hemispheres. After placement, the surface coil was matched and tuned to the phosphorus frequency. Arterial and venous lines were inserted for blood gas measurement and drug infusion, but no instrumentation for metabolic or blood flow measurement was applied. All ferromagnetic surgical instruments were removed or substituted with plastic equivalents before being placed in the magnet.

\section{Data collection}

Blood flow measurement. Cerebral blood flow was measured by radioactive microspheres ${ }^{7}$ at 20 minutes after the initiation of $\mathrm{CPB}$, at 30 minutes into cooling, and at 15 minutes, $45 \mathrm{~min}$ utes, and 225 minutes after reperfusion. Microspheres $15 \mu \mathrm{m}$ in diameter, labeled with one of the following radioactive nuclides- ${ }^{141} \mathrm{Ce},{ }^{113} \mathrm{Sn},{ }^{85} \mathrm{Sr},{ }^{95} \mathrm{Nb}$, and ${ }^{46} \mathrm{Sc}$ - were suspended in $0.5 \mathrm{ml}$ of $10 \%$ dextran (approximately $2.5 \times 10^{6}$ microspheres). The suspension was injected into a side port on the arterial tubing $50 \mathrm{~cm}$ from the tip of the cannula to ensure complete mixing. A measured quantity of blood (approximately $7 \mathrm{ml}$ ) as reference was withdrawn at a constant rate by a syringe pump (dye-dilution pump model 2603, Harvard Apparatus Co., South Natick, Mass.) from the thoracic aortic catheter throughout the duration of and until 30 seconds after completion of the microsphere injection. At the end of the experiment, the brain was taken out and weighed for measurement of water content. It was divided into the right and the left cerebral hemispheres, basal ganglia, midbrain, cerebellum, and lower brainstem (pons and medulla oblongata). After desiccation and measurement of dry weight, the brain parts were dissolved in $2 \mathrm{~N}$ potassium hydroxide-methanol solution and the radioactivity was counted (Compugamma 1282, LKB Instruments, Wallac, Finland) with a spillover correction between the nuclides. The regional blood flow was calculated from the rate of withdrawal of the reference blood and the ratio of the radioactivity of the organ to the reference blood.

Metabolic measurements. Blood gas tensions and $\mathrm{pH}$, hemoglobin, plasma glucose, and lactate concentrations were measured in arterial and jugular venous blood before CPB and after each microsphere injection. Blood gas and hemoglobin were measured with a blood gas analyzer (model 278, Ciba Corning, Medfield, Mass.). Plasma glucose and lactate levels were determined by the glucose oxidase method and enzymatic fluorometric micromethod, respectively. Cerebral oxygen and glucose consumption were calculated from the difference between the arterial and internal jugular venous oxygen contents and glucose concentrations and total cerebral blood flow. The oxygen content was calculated by the following formula:

$$
\begin{gathered}
\mathrm{O}_{2} \text { content }=1.34 \times \text { hemoglobin }(\mathrm{gm} / \mathrm{dl}) \times \mathrm{O}_{2} \text { saturation }+ \\
0.003 \times \mathrm{PO}_{2}
\end{gathered}
$$

where $\mathrm{Po}_{2}$ is oxygen tension. Lactate concentrations in the return effluent of cerebroplegic solutions also were analyzed.

$M R S$. Phosphorus 31 magnetic resonance spectra were acquired in the Fourier transform mode on a custom-built spectrometer with the Oxford horizontal-bore $4.7 \mathrm{~T}$ magnet and surface coil, as described previously in detail. ${ }^{6,8}$ The field homogeneity was optimized with the brain water signal. Spectra were acquired with a 90-degree excitation pulse of $60 \mu \mathrm{sec}$. Each spectrum was the average of 128 acquisitions ( 9 minutes). Peak areas of inorganic phosphate, creatine phosphate, and $\beta$-nucleoside triphosphate were determined by Lorentzian curve fitting and peak integration (NMRI Software, New Methods Research, East Syracuse, N.Y.). Changes in adenosine triphosphate (ATP) concentration were assessed from the $\beta$-nucleoside triphosphate peak area. The inorganic phosphate, creatine phosphate, and ATP data are reported as percentage of the baseline data obtained during the last 9 minutes of the initial full-flow normothermic bypass period. The intracellular $\mathrm{pH}$ in the brain ( $\mathrm{pHi}$ ) was calculated from the chemical shift of the inorganic phosphate peak relative to the creatine phosphate peak (D), by means of the following equation:

$$
\left.\mathrm{pHi}=\mathrm{pK}^{\prime}+\log [\mathrm{D}-\mathrm{Da}) /(\mathrm{Db}-\mathrm{D})\right]
$$

where $\mathrm{pK}^{\prime}=6.700, \mathrm{Da}=3.148$, and $\mathrm{Db}=5.695$ for a temperature of $37^{\circ} \mathrm{C}$ and $\mathrm{pK}^{\prime}=6.780, \mathrm{Da}=3.227$, and $\mathrm{Db}=5.653$ for $15^{\circ} \mathrm{C} .^{9}$ The equation for $15^{\circ} \mathrm{C}$ was used to calculate the inorganic phosphate during hypothermia, and the equation for $37^{\circ} \mathrm{C}$ was used for all other spectra.

Vascular reactivity to vasodilators. To assess preservation of endothelial function, we evaluated vascular reactivity to the endothelium-dependent vasodilator, acetylcholine, and endothelium-independent vasodilator, nitroglycerin, in the carotid circulation by calculating vascular resistance change during drug infusion. The concentration of acetylcholine solution was calculated to give a concentration of $10^{-7} \mathrm{~mol} / \mathrm{L}$ in the arterial blood at a certain infusion rate assuming that the solution mixed 


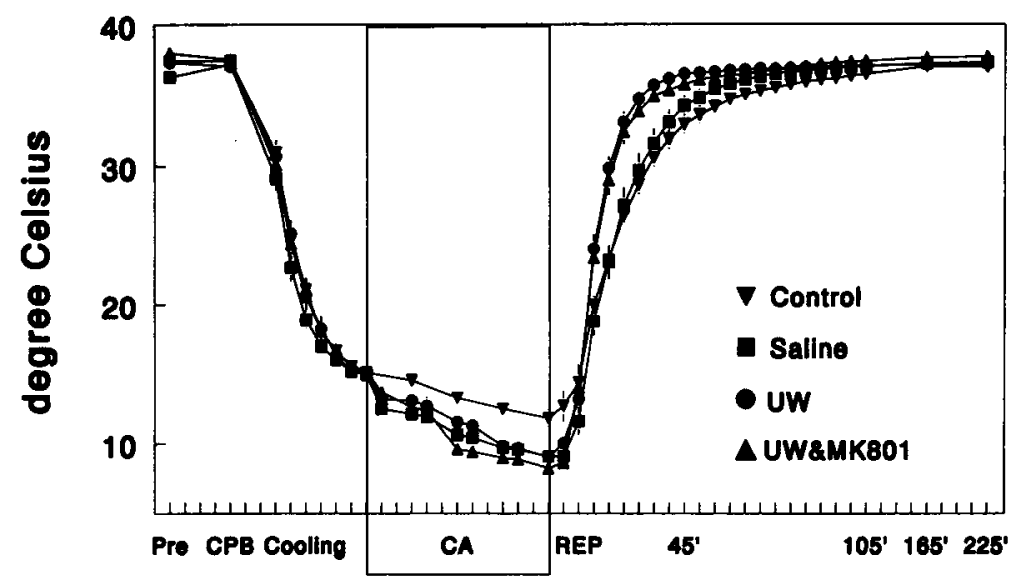

Fig. 1. Brain temperature. Pre, Before initiation of cardiopulmonary bypass; $C P B$, normothermic cardiopulmonary bypass; Cooling, hypothermic cardiopulmonary bypass; $C A$, total circulatory arrest; $R E P$, reperfusion and rewarming; $X^{\prime}, \mathrm{X}$ minutes of reperfusion.

thoroughly with the perfusate in the arterial tubing during infusion. The concentration of nitroglycerin solution was calculated to give an arterial concentration of $10^{-5} \mathrm{~mol} / \mathrm{L}$. These concentrations were selected after preliminary experiments that determined a dose-response relationship for cerebral vascular resistance. A near linear dose-response relationship was observed in the range of concentrations used. The solutions were infused into the side port on the arterial tubing used for microsphere injection for a period of 60 seconds by an infusion pump (model 975, Harvard Apparatus). Vascular resistance response was defined as percent change in vascular resistance calculated from baseline and maximum change in blood pressure and carotid blood flow measured by the electromagnetic flowmeter during the infusion assuming a venous pressure of zero. The evaluation was made at 10 minutes after initiation of CPB (prehypothermic circulatory arrest baseline) and at 60 and 230 minutes after reperfusion.

Brain water content. The whole brain was weighed immediately after the experiment (wet weight) and after desiccation for 72 hours at $60^{\circ} \mathrm{C}$ (dry weight). The brain water content was calculated as (Wet weight - Dry weight) $/$ (Wet weight).

Experimental groups. Twelve piglets $(n=7$ for blood flow and metabolic study and $\mathrm{n}=5$ for MRS study) had a $50 \mathrm{ml} / \mathrm{kg}$ dose of saline ( $0.9 \%$ sodium chloride injection, USP, Abbott Laboratories, North Chicago, Ill.) infused in the carotid artery system through the catheter in the subclavian artery at the initiation of hypothermic circulatory arrest. Doses of $10 \mathrm{ml} / \mathrm{kg}$ were repeated every 30 minutes during the hypothermic circulatory arrest (group CPS). Eleven ( $n=5$ for blood flow and metabolic study and $n=6$ for MRS study) received the same volumes of UW solution (Viaspan, Dupont Pharmaceuticals, Wilmington Del.) (group CPU). Ten piglets ( $n=5$ for blood flow and metabolic study and $n=5$ for MRS study) received the UW solution with a $7.5 \mathrm{mg} / \mathrm{L}$ dose of MK-801, an $N$-methylD-aspartate antagonist (Biochemical Research Laboratories, Natick, Mass.) (group CPM). The dose of MK-801 was determined from calculated blood concentration in our previous study ${ }^{10}$ which explored systemic administration of MK-801 in a similar piglet model of hypothermic circulatory arrest. In that study, MK-801 was associated with enhanced recovery. All solutions were infused at $4^{\circ} \mathrm{C}$. Glutathione $(3 \mathrm{mmol} / \mathrm{L}$, reduced form, Sigma Chemical Company, St. Louis, Mo.) was added to the UW solution immediately before use. ${ }^{11,12}$ The $\mathrm{pH}$ of the solutions was $6.30 \pm 0.01$ (saline), $7.10 \pm 0.02$ (UW), $7.00 \pm 0.02$ (UW $+\mathrm{MK}-801$ ). Oxygen tension of the solutions ranged from 200 to $290 \mathrm{~mm} \mathrm{Hg}$ as measured at $37^{\circ} \mathrm{C}$. The return effluent of the infused solution was drained and collected from a side arm from the venous cannula. Thirteen piglets ( $n=7$ for blood flow and metabolic study and $n=6$ for MRS study) received no solution and served as controls.

Statistics. All values are reported as mean \pm standard error of the mean. Analyses were conducted with a statistical analysis system (SPSS, SPSS Inc., Chicago, Ill.). Data were analyzed with two-way repeated-measures analysis of variance (ANOVA). The paired $t$ test was used to detect differences within a group, and one-way ANOVA and Student-Newman-Keuls test were used to detect differences between groups.

\section{Results}

Experimental conditions. Arterial oxygen tensions were above $200 \mathrm{~mm} \mathrm{Hg}$ and arterial carbon dioxide tensions were controlled within a range of 25 to $55 \mathrm{~mm} \mathrm{Hg}$ $(40.1 \pm 0.3 \mathrm{~mm} \mathrm{Hg})$ in all animals throughout the experiments. All groups had a metabolic acidosis $(7.27 \pm 0.01) 5$ minutes after beginning reperfusion (before bicarbonate injection), but $\mathrm{pH}$ was $7.34 \pm 0.01$ at 15 minutes of reperfusion and $7.35 \pm 0.01$ at 45 minutes of reperfusion. No significant differences (ANOVA $p>0.13$ ) were detected among the four groups in arterial $\mathrm{pH}$, oxygen and carbon dioxide tensions, and rectal temperatures at all measurements (data not shown). Nasopharyngeal temperature during hypothermic circulatory arrest was significantly lower in the cerebroplegiatreated groups than in the control group $\left(\mathrm{CNT}, 20.8^{\circ} \pm\right.$ $0.8^{\circ} \mathrm{C}$; CPS, $17.2^{\circ} \pm 0.7^{\circ} \mathrm{C}$; CPU, $17.7^{\circ} \pm 0.5^{\circ} \mathrm{C}$; $\mathrm{CPM}, 16.6 \pm 0.5^{\circ} \mathrm{C}$, at the end of hypothermic circula- 

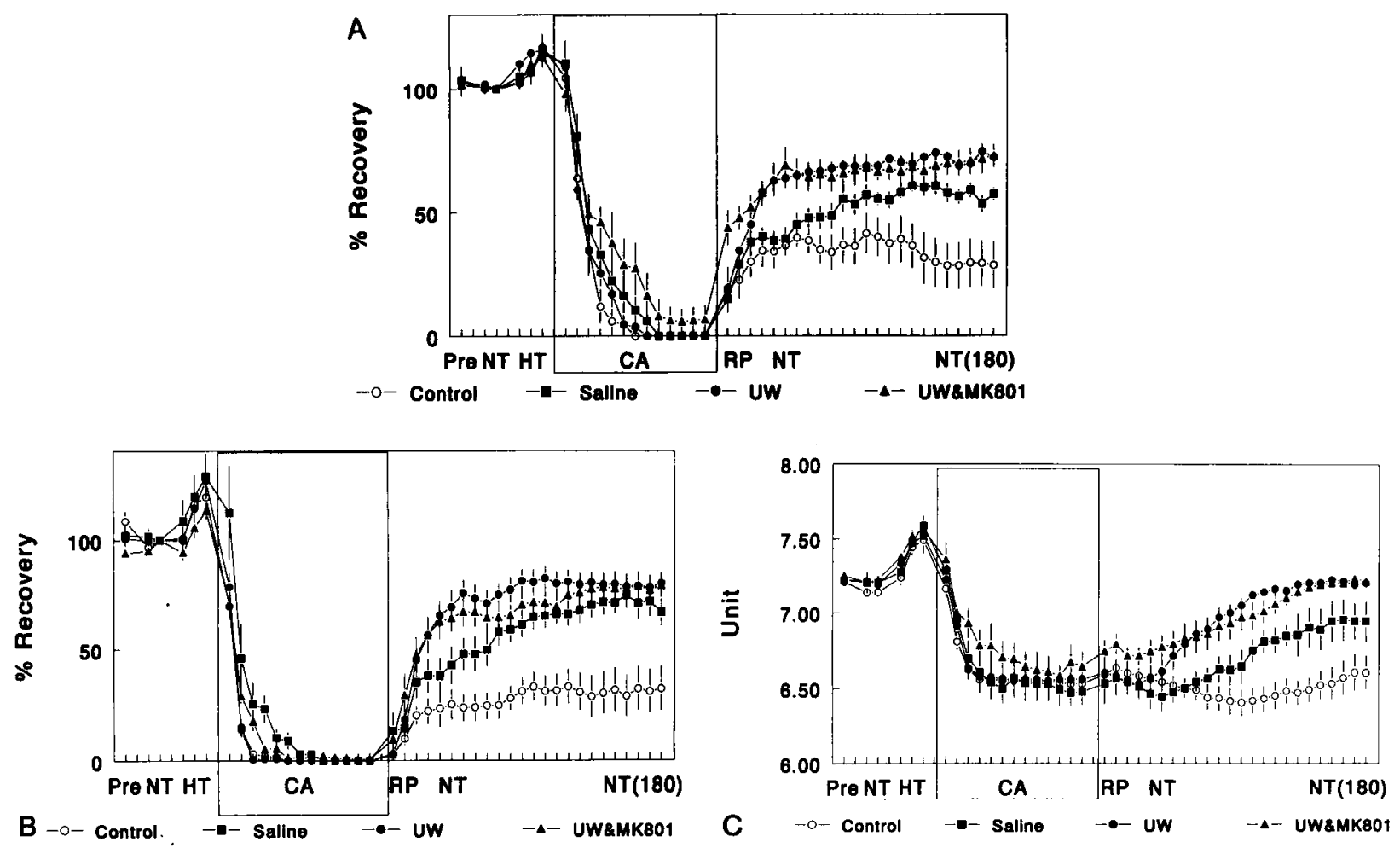

Fig. 2. Cerebral high-energy phosphates and intracellular pH. A, ATP. B, Phosphocreatine. C, Intracellular pH. Pre, Before initiation of cardiopulmonary bypass; $N T$, normothermic cardiopulmonary bypass; $H T$, hypothermic cardiopulmonary bypass; $C A$, total circulatory arrest; $R P$, reperfusion and rewarming; $N T(180)$, after 180 minutes of reperfusion at normothermia.

tory arrest). Brain temperature at the onset of hypothermic circulatory arrest was $15.0^{\circ} \pm 0.11^{\circ} \mathrm{C}$ and dropped to $13.0^{\circ} \pm 0.29^{\circ} \mathrm{C}$ after cerebroplegic infusion and stayed lower than control throughout the hypothermic circulatory arrest period. The nasopharyngeal and brain temperatures warmed faster in the CPU group during reperfusion than in the other groups (Fig. 1). Brain temperature returned to normothermic baseline levels within 2 hours of reperfusion in all groups.

Cerebral high-energy phosphates and intracellular pH (Fig. 2). In all animals, except for one in the group CPM, the phosphocreatine and nucleoside triphosphate concentrations became unmeasurable within 90 minutes of the onset of hypothermic circulatory arrest. The intracellular brain $\mathrm{pH}$ became acidotic during circulatory arrest with a tendency for group CPM to have a slower decline than other groups. Recovery of ATP $(p=0.004)$ and creatine phosphate $(p=0.002)$ was significantly faster during the first 45 minutes of reperfusion in the groups CPU and CPM relative to the control, but not relative to group CPS. The final recovery of ATP $(p<0.001)$ and creatine phosphate $(p=0.001)$ was sig- nificantly better in all the cerebroplegia-treated groups relative to the control group, and the recovery of ATP was further improved by UW solution and UW solution with MK-801 relative to saline (ATP $28.5 \% \pm 9.3 \%$ and creatine phosphate $32.4 \% \pm 9.9 \%$ in group CNT; ATP $53.7 \% \pm 2.6 \%$ and creatine phosphate $66.7 \% \pm 6.1 \%$ in group CPS; ATP $72.2 \% \pm 3.0 \%$ and creatine phosphate $79.8 \% \pm 11.4 \%$ in group CPU; ATP $72.9 \% \pm 4.6 \%$ and creatine phosphate $78.9 \% \pm 5.3 \%$ in group $\mathrm{CPM}$ ). Intracellular brain $\mathrm{pH}$ showed slower recovery than the highenergy phosphates. A period of further progression of the intracellular acidosis occurred during early reperfusion, which tended to be longer in groups CNT and CPS. The final recovery of intracellular brain $\mathrm{pH}$ was significantly better $(p<0.001)$ in all the cerebroplegia groups than in the control group $(6.57 \pm 0.11$ in group CNT, $6.90 \pm 0.14$ in group CPS, $7.14 \pm 0.02$ in group CPU, and $7.15 \pm 0.01$ in group CPM). It returned to the baseline levels within the observation period only in groups CPU and CPM, with the control animals showing a final intracellular brain $\mathrm{pH}$ that was profoundly acidotic.

Cerebral blood flow (Fig. 3). The mean value for all 


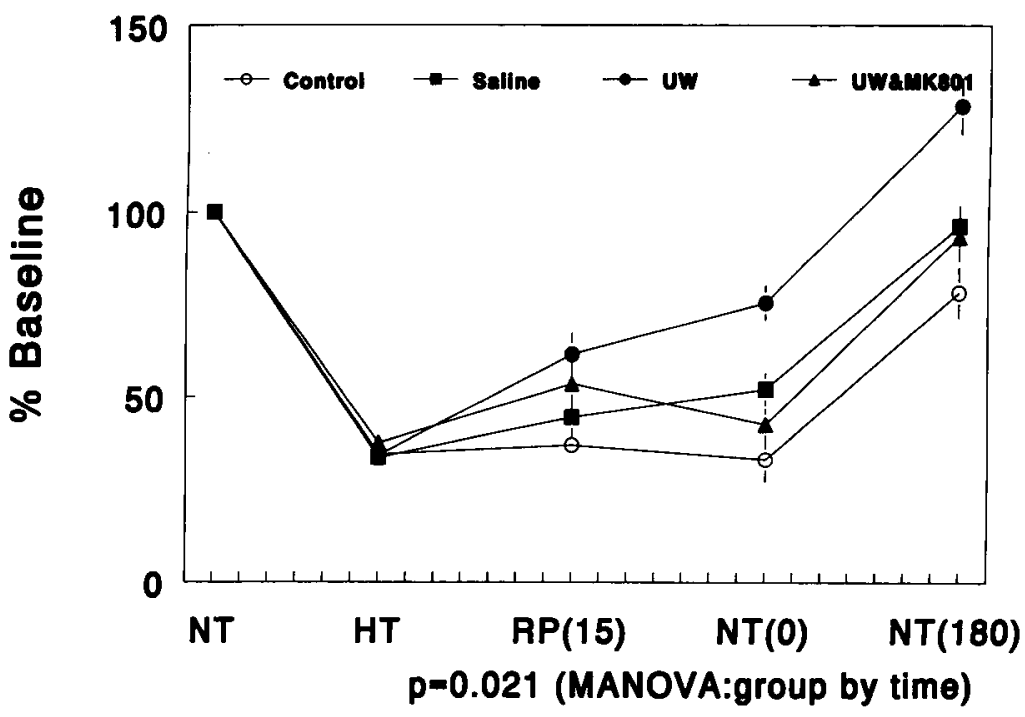

Fig. 3. Cerebral blood flow. $N T$, Normothermic cardiopulmonary bypass; $H T$, hypothermic cardiopulmonary bypass; $R P(15), 15$ minutes after initiation of reperfusion and rewarming after 2 hours of total circulatory arrest; $N T(0)$, after 45 minutes of rewarming, when normothermia was achieved; $N T(180)$, after 180 minutes of reperfusion at normothermia; $M A N O V A$, multivariate(two-way repeated-measures) analysis of variance.

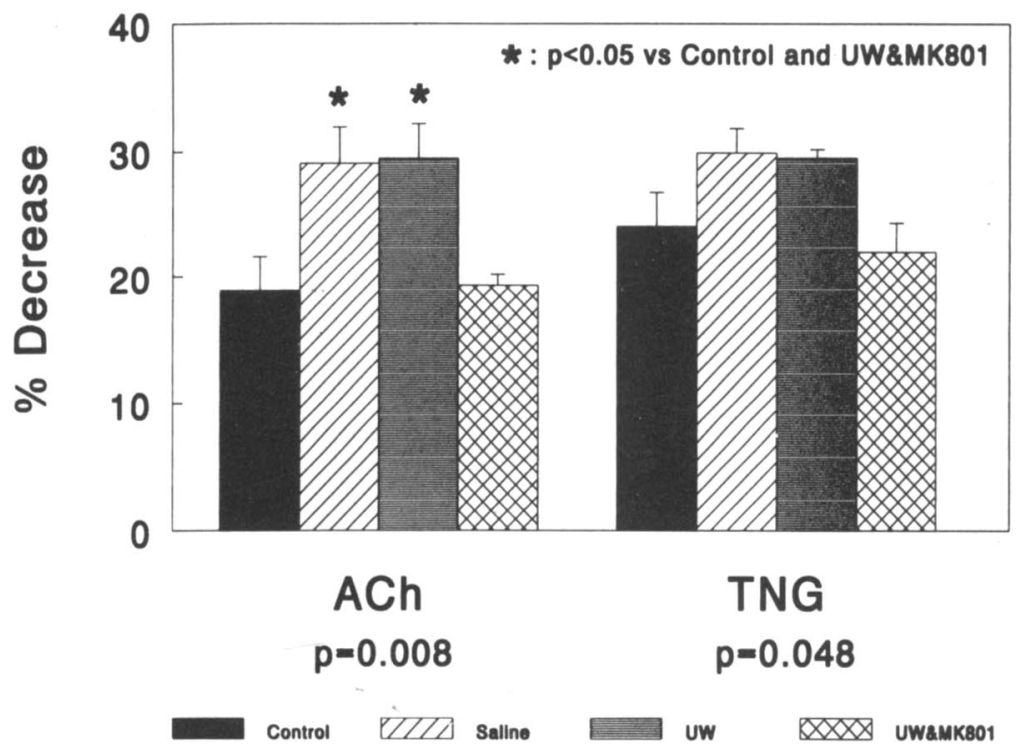

Fig. 4. Cerebral vascular response to vasodilators (at 60 minutes of reperfusion). $A C h$, Acetylcholine $\left(10^{-7} \mathrm{~mol} /\right.$ $\mathrm{L}) ; T N G$, nitroglycerin $\left(10^{-5} \mathrm{~mol} / \mathrm{L}\right)$.

groups for cerebral blood flow was $55.5 \pm 1.6 \mathrm{ml} / \mathrm{min}$ per $100 \mathrm{gm}$ tissue at the normothermic CPB baseline. No intergroup differences were observed. Recovery of cerebral blood flow was significantly greater in group CPU than in the control and saline-treated groups and was also grẹater than in group CPM. UW solution significantly improved the recovery of regional blood flow to the cere- bral hemispheres, basal ganglia, midbrain, and cerebellum but not to the lower brainstem (data not shown).

Vascular response to vasodilators (Fig. 4). No significant intergroup differences $(p>0.5)$ in cerebral vascular resistance response were observed at the normothermic CPB baseline. The groups CPS and CPU showed greater vascular resistance response to acetylcholine 

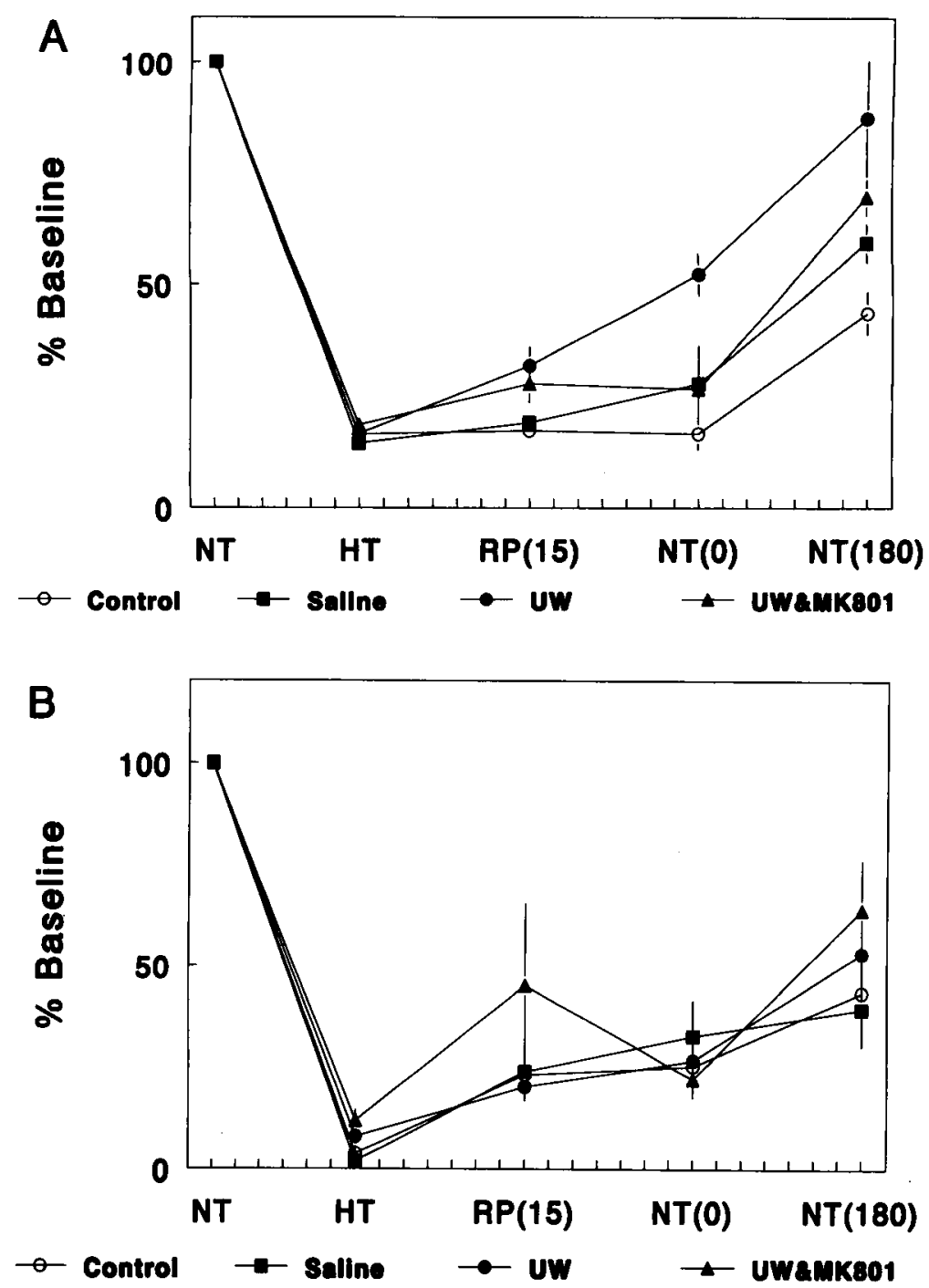

Fig. 5. Cerebral metabolism. A, Cerebral oxygen consumption. B, Cerebral glucose consumption. Abbreviations as for Fig. 3.

$(p=0.008)$ and nitroglycerin $(p=0.048)$ at 60 minutes of reperfusion relative to groups CNT and CPM. The same trend was seen at 230 minutes of reperfusion but did not attain statistical significance ( $p=0.069$ for acetylcholine and $p=0.133$ for nitroglycerin).

Cerebral oxygen and glucose consumption (Fig. 5). The mean values for all groups for cerebral oxygen consumption and cerebral glucose consumption were $2.49 \pm 0.13 \mathrm{ml} / \mathrm{min}$ per $100 \mathrm{gm}$ tissue and $6.83 \pm 0.58$ $\mathrm{mg} / \mathrm{min}$ per $100 \mathrm{gm}$ tissue at the normothermic CPB baseline. No intergroup differences were observed. Recovery of cerebral oxygen consumption was more complete and occurred earlier in the piglets receiving $\mathrm{UW}$ solution than in either the control or saline-treated piglets.
In contrast, no differences were observed between the groups in recovery of glucose consumption with the values remaining around $50 \%$ of the precooling value after 3 hours of normothermic reperfusion.

Lactate levels. The lactate levels in the cerebroplegic effluent were $2.42 \pm 0.20 \mathrm{mmol} / \mathrm{L}$ in group CPS, $2.69 \pm 0.20 \mathrm{mmol} / \mathrm{L}$ in group CPU, and $2.89 \pm 0.09$ $\mathrm{mmol} / \mathrm{L}$ in group CPM $(p=0.215)$. The systemic lactate levels were $2.69 \pm 0.19 \mathrm{mmol} / \mathrm{L}$ at baseline and rose to $8.48 \pm 0.39 \mathrm{mmol} / \mathrm{L}$ at 15 minutes of reperfusion and stayed high until the end of reperfusion $(7.07 \pm 0.60$ $\mathrm{mmol} / \mathrm{L})$. No significant intergroup differences were apparent at any time.

Brain water content (Fig. 6). The brain water content 


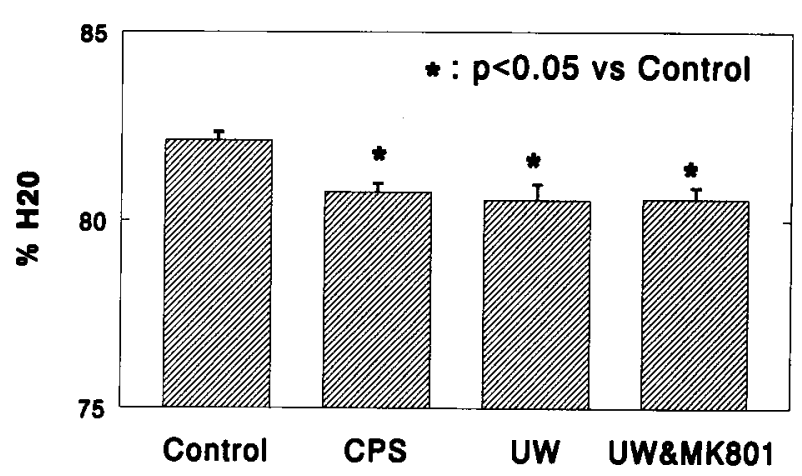

Fig. 6. Brain water content. CPS, Saline cerebroplegic solution; $U W$, University of Wisconsin solution.

at the end of experiment was significantly lower in the cerebroplegia-treated groups $(80.7 \% \pm 0.3 \%$ in group CPS, $80.5 \% \pm 0.4 \%$ in group CPU, and $80.6 \% \pm 0.3 \%$ in group CPM) than in the control group $(82.1 \%$ $\pm 0.2 \%$ ).

\section{Discussion}

The present study has shown that simple saline infusion at $4^{\circ} \mathrm{C}$ improves the short-term recovery of cerebral blood flow and metabolism after 2 hours of hypothermic circulatory arrest. Modification of the solution with UW solution further improves the recovery. The excitatory neurotransmitter antagonist MK-801 does not augment the protective effects of UW solution and reduces the recovery of cerebral blood flow.

Hypothermia is the basic strategy used to reduce ischemic injury during hypothermic circulatory arrest. ${ }^{13,14}$ The protective effect of hypothermia is believed to be derived mostly from a reduction in cerebral energy requirements, which is reflected in decreased cerebral oxygen consumption. In the present study, cerebral oxygen consumption decreased to a mean of $16.0 \%$ of normothermic baseline at a nasopharyngeal temperature of $15^{\circ} \mathrm{C}$, suggesting a temperature coefficient of 2.4 . If reduction in the metabolic rate is the sole neuroprotective effect of hypothermia, this reduction in cerebral oxygen consumption should extend the safe duration of hypothermic circulatory arrest from about 5 minutes at $37^{\circ} \mathrm{C}$ to 40 minutes at $15^{\circ} \mathrm{C}$. In fact, this is close to the upper limit of safe duration of 30 to 45 minutes suggested by our own clinical studies (the Boston Circulatory Arrest study),${ }^{15}$ as well as other clinical and experimental studies. ${ }^{1,16}$ However, surgical repair of complex cardiac anomalies may require a circulatory arrest time exceeding 60 minutes. Further improvement in cerebral protection during circulatory arrest is needed to minimize neurologic morbidity. In this study, the intermittent per- fusion of cerebroplegic solution at $4^{\circ} \mathrm{C}$ dropped the brain temperature by $2^{\circ} \mathrm{C}$. Applying the temperature coefficient of 2.4 suggests the safe limit should be extended by only $5 \%$. In a preliminary experiment, we aimed to reduce the brain temperature below $10^{\circ} \mathrm{C}$ by using cerebroplegia but found that a volume of $200 \mathrm{ml} / \mathrm{kg}$ of $4^{\circ} \mathrm{C}$ saline was needed to achieve such temperatures. Therefore the direct hypothermic effect of cerebroplegia is likely to be limited. Furthermore, this suggests that the improved recovery seen with the cold saline infusion may not result solely from a simple temperature effect on metabolism. Washing out neurotoxic metabolites produced during ischemia, and absence of glucose in the solution, thereby reducing lactate production during ischemia, may have contributed to the improved recovery. ${ }^{17,18}$

The UW solution was developed for cold storage of organs for transplantation. ${ }^{19}$ Improved organ preservation has been reported in the liver, kidney, pancreas, and heart. ${ }^{20}$ It does not contain glucose or any other substrates for energy production, and therefore it does not preserve cellular high-energy phosphate levels during ischemia, as was observed in the present study and in studies of other organs. ${ }^{21,22}$ The beneficial effects of UW solution appear to be due to other cellular protective mechanisms during hypothermic ischemia and reperfusion. Adenosine, glutathione, allopurinol, and lactobionate seem to be particularly important components for the improved preservation.

Adenosine is an endogenous neuroprotective agent. ${ }^{23,24}$ High levels of endogenous intracellular adenosine that result from a breakdown of ATP during ischemia depress cellular metabolic rate. Adenosine also blocks the release of the neurotransmitter glutamate ( $\mathrm{Al}$ receptor) ${ }^{25}$ Adenosine thereby may reduce the severity of excitotoxic injury. In addition, adenosine is a potent vasodilator (A2 receptor) and also blocks neutrophil activation (A2 receptor). ${ }^{26}$ We observed a hyperemic response in animals receiving $U W$ solution alone that was not seen in the other groups (see Fig. 3). This hyperemia may have contributed to the more rapid warming of the brain during the reperfusion period, as well as to the more rapid recovery of intracellular $\mathrm{pH}$ and ATP. Detrimental effects of blocking adenosine receptors by antagonists ${ }^{27,28}$ and protective effects of exogenous adenosine agonists $^{29,30}$ on ischemic brain injury have been reported previously.

Glutathione is an intracellular compound that is essential for the reduction of cytotoxic agents, including hydrogen peroxide, lipid peroxides, and free radicals. These agents are thought to have important roles in reperfusion injury. Cellular glutathione is depleted during ischemia. ${ }^{31}$ It has been demonstrated in liver ${ }^{32,33}$ and 
kidney preservation ${ }^{34,35}$ that the reduced form of glutathione plays an important role in the efficacy of UW solution. Allopurinol acts both as an inhibitor of xanthine oxidase and as a scavenger of free radicals. Xanthine oxidase can produce superoxide radicals by catalyzing oxidation of hypoxanthine during reperfusion. The role of xanthine oxidase in cerebral ischemia/reperfusion injury seems limited ${ }^{36,37}$ However, beneficial effects of allopurinol in reducing cerebral ischemic injury have been reported. ${ }^{38,39}$ Lactobionate is an impermeant anion and has been demonstrated to have important effects on suppressing cell swelling during cold storage of the liver. ${ }^{32}$ Other components of UW solution include raffinose, an impermeant trisaccharide that may play a role in prevention of cellular swelling, and hydroxyethyl starch, which acts as colloid to prevent interstitial edema. However, because brain water was the same in all the cerebroplegia groups, the role of these latter two compounds in the cerebroplegia may be less important.

There is evidence that "excitotoxity" 40,41 may play a role in neurologic complications after hypothermic circulatory arrest. Redmond and associates ${ }^{42}$ recently reported selective loss of cells with a high concentration of $N$-methyl-D-aspartate receptors after 2 hours of deep hypothermic circulatory arrest in the dog. In a prospective clinical study of hypothermic circulatory arrest with continuous postoperative electroencephalographic monitoring, we noted a high incidence of seizures, which may be excitotoxic in origin. ${ }^{15}$ Postoperative seizures have been correlated with worse motor development at 1 year of age (unpublished data from Boston Circulatory Arrest Study).

MK-801 is a noncompetitive $N$-methyl-D-aspartate receptor antagonist, which blocks $\mathrm{Ca}^{2+}$ influx triggered by excitatory transmitters and decreases the delayed neuronal damage of excitotoxcity. ${ }^{43-45}$ The neuroprotective effects of MK-801 are well established in focal cerebral ischemia. ${ }^{46,47} \mathrm{We}^{10}$ have demonstrated beneficial effects of MK-801 on postischemic recovery of high-energy phosphates after hypothermic circulatory arrest in our piglet model. However, in the present study MK-801 failed to add to the beneficial effects of UW solution on the postischemic recovery. The inhibitory effects of adenosine on excitatory amino acid release may partly explain the lack of an additional effect of MK-801 in the presence of UW solution. Another possibility is that the reduced cerebral blood flow recovery seen with MK-801 relative to UW solution alone might have offset the protective effects of MK-801. The effects of MK-801 on cerebral blood flow have not been well studied. MK-801 could reduce cerebral blood flow by $N$-methyl-D-aspartate receptor blockade. Stimulation of $N$-methyl-D-aspartate receptors has been shown to increase nitric oxide (intraneuronal) production. Both neuronal nitric oxide production and endothelial production have a role in cerebral blood flow regulation. However, our finding that cerebral vascular reactivity to acetylcholine (endogenous nitric oxide production by endothelial cells) and to nitroglycerin (exogenously derived nitric oxide) were both reduced by MK- 801 relative to UW solution alone suggests a direct vasoconstrictive action of MK-801. Torregrosa and colleagues ${ }^{48}$ have also reported a direct vasoconstrictive effect of MK-801.

The final ATP recovery of $73 \%$ at the end of $225 \mathrm{~min}-$ utes of reperfusion in the UW groups, although better than the other groups, is nevertheless less satisfactory than the recovery of $90 \%$ after 1 hour of hypothermic circulatory arrest in our previous study using the same model. ${ }^{6}$ Furthermore, in contrast to the previous study by Robbins, Balaban, and Swain ${ }^{2}$ using a simple crystalloid cerebroplegic solution, we continued to see complete loss of measurable high-energy phosphates as we had in previous studies in which cerebroplegia was not used. Perhaps use of the pH-stat strategy rather than alpha-stat may have improved recovery. We chose to use alpha-stat in this study despite our previous findings suggesting improved recovery with $\mathrm{pH}$-stat, ${ }^{8}$ because alpha-stat continues to be widely used clinically and we wished to observe a maximal effect from the cerebroplegic solution. Perhaps further modification of the cerebroplegic solution may improve recovery. The high potassium concentration $(140 \mathrm{mEq} / \mathrm{L})$ in the standard UW solution raises a concern. High potassium concentrations depolarize the neuronal membrane and activate voltage-dependent ion channels including the calcium ion channel. Although UW solution contains no calcium, calcium ions in the interstitial space may not be washed out completely. Calcium ion influx plays an important role in ischemic neuronal injury. ${ }^{49}$ It has been reported that reversing the sodium/potassium concentration ratio does not alter the protective effects of UW solution in the liver or kidney. However, just as with cardioplegic solutions, ${ }^{50}$ the protective effects of UW solution may be improved by reversing the sodium/potassium ratio in an "excitable" tissue like the brain. Further studies are needed to determine optimal composition of the cerebroplegic solution.

The short-term nature of this study, with no correlation with neurologic outcome or histopathology, is one of the important limitations of this study. Nevertheless, it is difficult to demonstrate subtle differences in neurologic damage in areas not responsible for motor function or consciousness by behavioral and neurologic evaluation in animals. In addition, neurologic scoring systems tend to be biased by death, which may not be due to neurologic 
injury. However, the long-term consequences of cold infusion of UW solution into the brain should be studied over the long term in experimental models. Bailes and colleagues $^{51}$ have reported complete neurologic recovery after continuous whole-body crystalloid perfusion at a temperature of $1.5^{\circ}$ to $7.5^{\circ} \mathrm{C}$ for 3 hours in a long-term experiment in dogs. In addition, Crittenden and colleagues ${ }^{3}$ described survival free of neurologic deficit in five of seven sheep subjected to 2 hours of hypothermic circulatory arrest with infusion of a simple crystalloid cerebroplegic solution.

In conclusion, this study confirms that cold cerebroplegic solution can improve short-term recovery of cellular energetics and blood flow after prolonged hypothermic circulatory arrest. In addition, it suggests that various pharmacologic additives can enhance the recovery achieved with a simple crystalloid solution.

We thank Mark A. Cioffi for his technical assistance and Laura Young for preparation of the manuscript. We also wish to pay tribute to Leo Neuringer, Ph.D., now deceased, who gave us advice and support in our work at the High Field NMR Facility for Biomedical Research at the Massachusetts Institute of Technology. Thanks also to Dupont Pharmaceuticals, which donated the University of Wisconsin solution.

\section{REFERENCES}

1. Kirklin JW, Barratt-Boyes BG. Hypothermia, circulatory arrest, and cardiopulmonary bypass. In: Cardiac surgery. 2nd ed. New York: Churchill Livingstone, 1993:73.

2. Robbins RC, Balaban RS, Swain JA. Intermittent hypothermic asanguineous cerebral perfusion (cerebroplegia) protects the brain during prolonged circulatory arrest: a phosphorus 31 nuclear magnetic resonance study. J THORAC CARdiovasc Surg 1990;99:878-84.

3. Crittenden MD, Roberts CS, Rosa L, et al. Brain protection during circulatory arrest. Ann Thorac Surg 1991; 51:942-7.

4. Aoki M, Jonas RA, Nomura F, et al. Effects of aprotinin on acute recovery of cerebral metabolism in piglets after hypothermic circulatory arrest. Ann Thorac Surg [In press].

5. Bengtsson F, Seisjo BK. Cell damage in cerebral ischemia: physiological, biochemical and structural aspects. In: Schurr A, Rigor BM, eds. Cerebral ischemia and resuscitation. Boston: CRC Press, 1990:215-33.

6. Kawata H, Fackler JC, Aoki M, et al. Recovery of cerebral blood flow and energy state after hypothermic circulatory arrest versus low-flow bypass in piglets. J THORAC CARDIOVASC SURG 1993;106:671-85.

7. Heymann MA, Payne BD, Hoffman JIE, Rudolph AM. Blood flow measurements with radionuclide-labeled particles. Prog Cardiovasc Dis 1977;20:55-79.

8. Aoki M, Nomura F, Stromski ME, et al. Effects of $\mathrm{pH}$ on brain energetics after hypothermic circulatory arrest. Ann Thorac Surg 1993;55:1093-103.

9. Kost GJ. pH Standardization for phosphorus-31 magnetic resonance heart spectroscopy at different temperatures. Magn Reson Med 1990;14:496-506.

10. Aoki M, Nomura F, Stromski ME, et al. Effect of MK-801 and NBQX on acute recovery of cerebral metabolism after hypothermic circulatory arrest. J Cereb Blood Flow Metab 1994;14:156-65.

11. Wincomb WN, Collins GM. 24-Hour rabbit heart storage with UW solution: effects of low-flow perfusion, colloid, and shelf storage. Transplantation 1989;48:6-9.

12. Astier A, Paul M. Instability of reduced glutathione in commercial Belzer cold storage solution. Lancet 1989; 2:556-7.

13. Norwood WI, Norwood CR, Castaneda AR. Cerebral anoxia: effect of deep hypothermia and pH. Surgery 1979; 86:203-9.

14. Norwood WI, Norwood CR, Ingwall JS, Castaneda AR, Fossel ET. Hypothermic circulatory arrest: 31-Phosphorus nuclear magnetic resonance of isolated perfused neonatal rat brain. J THORAC CARdiovasC Surg 1979;78:823-30.

15. Newburger JW, Jonas RA, Wernovsky G, et al. A comparison of the perioperative neurologic effects of hypothermic circulatory arrest versus low flow cardiopulmonary bypass in infant heart surgery. $\mathrm{N}$ Engl J Med 1993; 329:1057-64.

16. Greeley WJ, Kern FH, Ungerleider RM, et al. The effect of hypothermic cardiopulmonary bypass and total circulatory arrest on cerebral metabolism in neonates, infants, and children. J ThoraC CARdiovasC SuRG 1991;101:783-94.

17. Smith ML, Von Hanwehr R Siesjo BK. Changes in extraand intracellular $\mathrm{pH}$ in the brain during and following ischemia in hyperglycemic and in moderately hypoglycemic rats. J Cereb Blood Flow Metab 1986;6:574-83.

18. Corbett RJT, Laptook AR Nunnally RL, Hassan A, Jackson $\mathbf{J}$. Intracellular $\mathrm{pH}$, lactate, and energy metabolism in neonatal brain during partial ischemia measured in vivo by $31 \mathrm{P}$ and $1 \mathrm{H}$ nuclear magnetic resonance spectroscopy. J Neurochem 1988;51:1501-9.

19. Belzer FO, Southard JH. Principles of solid-organ preservation by cold storage. Transplantation 1988;45:673-6.

20. Belzer FO, D'Alessandro AM, Hoffmann RM, et al. The use of UW solution in clinical transplantation: a 4-year experience. Ann Surg 1992;215:579-85.

21. Swanson DK. Pasaoglu I, Berkoff HA Southard JA, Hegge JO. Improved heart preservation with UW preservation solution. J Heart Transplant 1988;7:456-67.

22. Nedelec JF, Capron-Laudereau AR, Dimicoli J, et al. Liver preservation: $31 \mathrm{P}$ and $13 \mathrm{C}$ NMR spectroscopic assessment of liver energy and metabolism after cold storage in Collins, Marshall, Ringer's lactate, UW and modified UW solutions. Transplant Proc 1989;21:1327-9.

23. Marangos PJ, Boulenger JP. Basic and clinical aspects of adenosinergic neuromodulation. Neurosci Biobehav Rev 1985;9:421-30. 
24. Dragunow M, Faull RL. Neuroprotective effects of adenosine. Trends Pharmacol Sci 1988;9:193-4.

25. Dolphin AC, Archer ER. An adenosine agonist inhibits and a cyclic AMP analogue enhances the release of glutamate but not GABA from slices of rat dentate gyrus. Neurosci Lett 1983;43:49-54.

26. Engler RL, Gruber HE. Adenosine: an autacoid. In: Fozzard HA, Haber E, Jennings RB, Katz AM, Morgan HE, eds. The heart and cardiovascular system: scientific foundations. 2nd ed. New York: Raven Press, 1991:1745-64.

27. Rudolphi KA, Keil M, Hinze HJ. Effect of theophylline on ischemically induced hippocampal damage in mongolian gerbils: a behavioral and histopathological study. J Cereb Blood Flow Metab 1987;7:74-81.

28. Sciotti VM, Roche FM, Grabb MC, Van Wylen DGL. Adenosine receptor blockade augments interstitial fluid levels of excitatory amino acids during cerebral ischemia. $\mathbf{J}$ Cereb Blood Flow Metab 1992;12:646-55.

29. Evans MC, Swan JH, Meldrum BS. An adenosine analogue, 2-chloroadenosine, protects against long term development of ischemic cell loss in the rat hippocampus. Neurosci Lett 1987;83:287-92.

30. Daval JL, Von Lubitz DKJE, Deckert J, Redmond DJ, Marangos PJ. Protective effect of cyclohexyladenosine on adenosine Al-receptors, guanine nucleotide and forskolin binding sites following transient brain ischemia: a quantitive autoradiographic study. Brain Res 1989;491:212-26.

31. Fuller BJ, Lunec J, Healing G, Simpkin S, Green CJ. Reduction of susceptibility to lipid peroxidation by deferoxamine in rabbit kidneys subjected to 24-hour cold ischemia and preservation. Transplantation 1987;43:604-6.

32. Jamieson NV, Lindell S, Sundberg R, Southard JH, Belzer FO. An analysis of the components in UW solution using the isolated perfused rabbit liver. Transplantation 1988; 46:512-6.

33. Boudjema K, Ellero B, Barguil Y, et al. Addition of reduced glutathione to UW solution: clinical impact in liver transplantation. Transplant Proc 1991;23:2341-3.

34. Biguzas M, Pablonski P, Howden BO, et al. Evaluation of UW solution in rat kidney preservation. II. The effect of pharmacological additives. Transplantation 1990;49:10515.

35. Southard JH, Van Gulik TM, Ametani MS, et al. Important components of the UW solution. Transplantation 1990;49:251-7.

36. Wajner M, Harkness RA. Distribution of xanthine dehydrogenase and oxidase activities in human and rabbit tissues. Biochem Biophys Acta 1989;991:79-84.

37. Lindsay S, Liu TH, Xu J, et al. Role of xanthine dehydro- genase and oxidase in focal cerebral ischemic injury to rat. Am J Physiol 1991;261:H2051-7.

38. Palmer C, Vannucci RC, Towfighi J. Reduction of perinatal hypoxic-ischemic brain damage with allopurinol. Pediatr Res 1990;27:332-6.

39. Mink RB, Dutka AJ, Hallenbeck JM. Allopurinol pretreatment improves evoked response recovery following global cerebral ischemia in dogs. Stroke 1991;22:660-5.

40. Olney JW, Hol OL, Rhee V. Cytotoxic effects of acidic and sulphur containing amino acids on the infant mouse central nervous system. Exp Brain Res 1971;14:61-76.

41. Rothman SM. Synaptic activity mediates death of hypoxic neurons. Science 1983;220:536-7.

42. Redmond JM, Gillinov AM, Zehr KJ, et al. Glutamate excitotoxicity: a mechanism of neurologic injury associated with hypothermic circulatory arrest. J THORAC CARDIOVASC SURG 1994;107:776-87.

43. Berdichevsky E, Riveros N, Sanchez-Armass S, Orrego F. Kainate, N-methylaspartate and other excitatory amino acids increase calcium influx into rat brain cortex cells in vitro. Neurosci Lett 1983;36:75-80.

44. Wong EHF, Kemp JA, Priestley T, Knight AR Woodruff GN, Iversen LL. The anticonvulsant MK-801 is a potent N-methyl-D-aspartate antagonist. Proc Natl Acad Sci USA 1986;83:7104-8.

45. Choi DW. Glutamate neurotoxicity in cortical cell culture is calcium dependent. Neurosci Lett 1985;58:293-7.

46. Gill R, Foster AC, Woodruff GN. Systemic administration of MK-801 protects against ischemia-induced hippocampal neurodegeneration in the gerbil. J Neurosci 1987;7: 3343-9.

47. Meldrum B. Protection against ischaemic neuronal damage by drugs acting on excitatory neurotransmission. Cerebrovasc Brain Metab Rev 1990;2:27-57.

48. Torregrosa G, Salom JB, Miranda FJ, Alabadi JA, Alvarez JA, Alborch E. In vivo and in vitro effects of the NMDA receptor antagonist dizocilpine(MK-801) on the cerebrovascular bed of the goat. J Cereb Blood Flow Metab 1991;11(Suppl 2):S287.

49. Siesjo BK, Bengtsson F. Calcium fluxes, calcium antagonists, and calcium-related pathology in brain ischemia, hypoglycemia, and spreading depression: a unifying hypothesis. J Cereb Blood Flow Metab 1989;9:127-40.

50. Hearse DJ, Braimbridge MV, Jynge P. Protection of the ischemic myocardium: cardioplegia. Chap. 7. Components of cardioplegic solutions. New York: Raven Press, 1981.

51. Bailes JE, Leavitt ML, Teeple E Jr, et al. Ultraprofound hypothermia with complete blood substitution in a canine model. J Neurosurg 1991;74:781-8. 